\title{
Changing trends in the management of corpus luteum haemorrhage
}

\author{
Avantika Gupta ${ }^{1}$, Deepthi Nayak ${ }^{2}$, Purnima Tiwari ${ }^{1 *}$
}

\begin{abstract}
${ }^{1}$ Department of Obstetrics and Gynecology, All India Institute of Medical Sciences, Nagpur, Maharashtra, India ${ }^{2}$ Department of Obstetrics and Gynecology, Jawaharlal Institute of Postgraduate Medical Education and Research, Pondicherry, Tamil Nadu, India
\end{abstract}

Received: 29 May 2021

Accepted: 30 June 2021

*Correspondence:

Dr. Purnima Tiwari,

E-mail: purnima_gupta30@yahoo.co.in

Copyright: () the author(s), publisher and licensee Medip Academy. This is an open-access article distributed under the terms of the Creative Commons Attribution Non-Commercial License, which permits unrestricted non-commercial use, distribution, and reproduction in any medium, provided the original work is properly cited.

\section{ABSTRACT}

Corpus luteal haemorrhage usually causes only mild symptoms and resolve spontaneously, however, it can cause massive bleeding in certain patients with coagulation or bleeding disorders. Over a decade, the management of corpus luteum haemorrhage has shifted from surgical to conservative management. This article focuses on selection of patients for conservative management so that the morbidities associated with the surgery can be avoided. Conservative management includes optimization of oxygen carrying capacity of blood, correction of coagulopathy and appropriate analgesia. It can be recurrent in certain high-risk group of patients who will need long term suppression of ovulation.

Keywords: Corpus luteal cyst, Hemoperitoneum, Cyst rupture, Laparotomy, CT scan

\section{INTRODUCTION}

Corpus luteal cyst (CLC) can form in any woman of reproductive age group, as a result of abnormal follicle maturation. As follicle develops into CLC, bleeding can occur into it and when intra-cystic pressure increases beyond its capacity it can rupture into the peritoneum. Usually, this condition doesn't produce many symptoms, except mild lower abdominal pain. Two-thirds of CLCs involve right ovary and rupture occurs most commonly on menstrual day $20-16 .^{1}$

Normal corpus luteum basement membrane degenerates and blood vessels grow into it due to various angiogenic factors. Fibrin formation stops any bleeding in patients with normal hemostatic mechanism but in those patients having coagulopathy, bleeding continues into cyst, and finally, it can rupture into peritoneum leading to significant hemoperitoneum. CLC rupture can be the first presentation of bleeding diathesis. Patients on long term anticoagulants such as warfarin are more prone to this condition. Various case reports are available describing CLC rupture in patients on long term Warfarin for metallic prosthetic valve, APLA syndrome and congenital hypofibrinogenemia. ${ }^{2-6}$ The annual risk of the bleeding episode in patients on long term anticoagulation is 1.17.5\%. ${ }^{7}$ An INR above 4.0-4.5 is considered as a high risk for CLC rupture causing significant hemoperitoneum. ${ }^{5,8,9}$ Patients with INR of 3.0-4.4 also have a slight but significant increase in the risk of bleeding episodes as compared to those having INR of less than 3.0. ${ }^{2,9}$ However, CLH is also possible in patients with INR in the normal or sub-therapeutic range. ${ }^{10}$

\section{DIAGNOSIS}

Diagnosis of CLC rupture can be delayed, owing to the presence of other conditions that can closely mimic its clinical presentation. Pain and tenderness in right iliac fossa can mimic appendicitis. The presence of hemoperitoneum along with adnexal mass can be due to ectopic pregnancy or adnexal torsion. Ultrasonography can be helpful to differentiate these conditions. Haemorrhagic cysts tend to evolve slowly into various stages of acute haemorrhage, clots formation and clot retraction, thus giving to various changing sonographic 
patterns. Classically, fresh blood is anechoic and in subacute stages clot shows fine reticular pattern followed by the appearance of retracting clot. Its echogenicity decreases with time and by 96 hours, it becomes entirely echo-free. ${ }^{11}$ Ruptured ectopic pregnancy with hemorrhage and ruptured corpus luteal cyst can have similar clinical presentation and diagnosis should be confirmed before contemplating on conservative management. CT scan aids in clinching the diagnosis by the appearance and size of the adnexal mass, cystic shadow and depth of the pelvic collection. ${ }^{12}$ Corpus luteum will appear like a wellcircumscribed unilocular lesion with inhomogeneous contrast enhancement and a thickened cyst wall on a CT scan. Source of bleeding can be identified by locating sentinel clot, which appears as an area of highest attenuation. In absence of availability of CT scan, USG can also be used which reveals an echogenic rim surrounding a cystic component in the adnexa along with hemoperitoneum. However, MRI is not preferred in acute settings due to its cost, long acquisition time, and limited availability. ${ }^{13}$

\section{MANAGEMENT}

Before 2-3 decades, management for all the cases of CLH used to be exploratory laparotomy followed by either cystectomy, wedge resection, or oophorectomy. Semchyshyn et al reviewed 29 cases from literature and added 6 cases of CLH managed by them from 1957 to $1978 .{ }^{3}$ Out of these 35 cases, 14 had unilateral salpingooophorectomy, 8 had hysterectomy and bilateral salpingooophorectomy, 4 had their ovaries oversewn and 4 had cystectomy; three patients died of haemorrhage. Tresch et al described a study done in 1975 in 6 cases of CLH out of which 3 were managed conservatively and 3 had surgical intervention. ${ }^{4}$ All 3 patients underwent BSO by the surgeon in anticipation of recurrence. A review of 173 surgical cases of CLH by Hallatt et al showed that most patients underwent either lutectomy, cystectomy, or wedge excision of the ovary. ${ }^{14}$ In this study, the decision for surgery was taken if hematocrit of blood obtained on culdocentesis was $>12 \%$.

After the 1980s only, management gradually changed to less radical surgeries instead of oophorectomy or wedge resection. Jamal et al did one retrospective study over one year in 1994 in women already operated for CLH. ${ }^{10}$ Suturing the bleeding site alone achieved hemostasis in 41 out of 46 women and oophorectomy was done in 5 patients. In the 1990s, non-surgical management began to be tried as one of the alternate approaches to patients with CLH. Raziel et al published a study in 1993 in 70 patients with CLH over 6 years. ${ }^{15}$ Out of these, 12 patients were successfully given conservative management and rest 58 women were operated directly. The higher rate of surgical intervention in these studies is probably due to the following factors: (a) cut off for the amount of hemoperitoneum was as less as $250 \mathrm{cc}$; (b) hematocrit of culdocentesis blood was taken as criteria for surgical intervention, which is not very specific; and (c) lack of availability of good resolution USG or CT scan in those days. $^{15}$

It was after the 1990s, conservative management was sought as initial management in hemodynamically stable patients with CLH. In such patients, conservative management is far better than the surgical approach because of decreased risk of reduced ovarian function as well as of postoperative infection and thromboembolism. Basis of conservative management is that the hemoperitoneum of up to 11 gets absorbed within a week and non-inflammatory ovarian bleeding is not associated with intra-abdominal adhesions. ${ }^{16}$ Since these cysts are hormonally driven, these tend to resolve in 4-6 weeks completely.

Management of CLH should be based on clinical symptoms and the size of hemoperitoneum. For hemodynamically stable patients with hemoperitoneum of less than 11 , conservative management is the best. It should include- (a) frequent monitoring of vitals of the patients and clinical pallor; (b) investigations such as hemoglobin, hematocrit, PT with INR which should be repeated 4-6 hourly in the initial 24 hours; (c) correction of coagulopathy by discontinuing anticoagulants. If anticoagulation has to be continued in certain situations like a metallic prosthetic valve, warfarin can be changed to heparin. Additionally, either fresh frozen plasma or plasma cell concentrate is given. The advantages of plasma cell concentrate are its immediate effect and less volume requirement, thus avoiding fluid overload. ${ }^{17}$ Thus in patients with heart disease on anticoagulation with CLH, plasma cell concentrate is the treatment of choice.

Vitamin $\mathrm{K}$ can be given as a single dose of $10 \mathrm{mg}$ intravenous to antagonize the effect of Warfarin. The subcutaneous or intramuscular route is not preferred in these patients. INR starts to drop within 2 hours of intravenous vitamin $\mathrm{K}$ and will normalize in 12-16 hours. ${ }^{17}$ Higher doses are avoided as it leads to warfarin resistance(a) adequate analgesia in the form of opioid analgesics. NSAIDs are better avoided in an acute episode of bleeding; and (b) pelvic fluid collection depth measurement on ultrasound or preferably CT scan as it gives fluid collection and fewer chances of misdiagnosis of the primary condition. ${ }^{18} \mathrm{CT}$ attenuation of more than 30 house-field Units is diagnosed as hemoperitoneum. ${ }^{1}$ The total depth of hemoperitoneum is a sum of the depth of anterior $\mathrm{Cul} \mathrm{de}$ sac plus the depth of the posterior $\mathrm{Cul} \mathrm{de} \mathrm{sac.} \mathrm{Former} \mathrm{is}$ measured as the distance from anterior peritoneum to anterior uterine wall and the latter is a measure of distance from the posterior uterine wall to the rectum. The total depth of $5.6 \mathrm{~cm}$ was associated with an increased risk of surgical intervention in a study done by Kim et al. ${ }^{18}$

\section{Management of patients with hemoperitoneum less than $1 l$}

There are various studies in which hemodynamically stable patients with hemoperitoneum of less than 11 were 
managed successfully on conservative management. Spinelli et al did a retrospective study from 2002-6 in 13 adolescent girls with CLH in which 11 were offered initial conservative management and two patients were taken immediately for surgery. ${ }^{19}$ Fong et al reviewed 47 cases of surgically treated patients from 2004-11, out of which 40 had hemoperitoneum of less than one litre. ${ }^{20}$ The higher rate of surgical intervention in this study was because $55 \%$ of cases were initially misdiagnosed. Raziel et al used a cut off of $250 \mathrm{cc}$ of hemoperitoneum for surgical intervention and thus patients underwent surgery directly. ${ }^{15}$

Kim et al reviewed 78 cases of CLH from 2008-13, 63 were managed successfully by conservative treatment, whereas only 15 underwent exploratory laparoscopy. ${ }^{18}$ In the same study, diastolic blood pressure of less than 70 $\mathrm{mmHg}$ and depth of total pelvic collection on CT scan of more than $5.6 \mathrm{~cm}$ were two determining factors for surgical intervention. Similarly, Lee et al reviewed 106 cases of corpus luteal cyst rupture with hemoperitoneum retrospectively and found that hemoperitoneum depth on CT of more than $5.8 \mathrm{~cm}$ had a sensitivity of $75.0 \%$ and specificity of $58.6 \%$ along with higher odds for surgical intervention $(\mathrm{OR}=5.786){ }^{21}$ The depth of hemoperitoneum and active bleeding from the cyst during the portal venous phase on CT scan are important predictors of surgical intervention among women with CLH. With the presence of active bleeding, the surgical intervention is almost $45.5 \%$ whereas it falls to $7.4 \%$ with the absence of active bleed and hemoperitoneum of $<5.8 \mathrm{~cm}$. Gupta et al managed two cases with hemoperitoneum of $800 \mathrm{cc}$ and 300 cc successfully with conservative management alone. ${ }^{2}$ In another study by Lee et al, out of 30 women with suspected CLH, 5 were given conservative management, 11 underwent laparotomy and 19 underwent laparoscopy. ${ }^{22}$ In the previous study, the authors didn't find any significant difference between surgical and conservative management.

\section{Management of patients with hemoperitoneum more than $1 l$}

In patients with hemoperitoneum of more than 11 , management should be individualized. In all studies where, conservative management was sought as first line management, CT scan was done to measure the amount of free fluid. With the advent of CT scan, it has become easier to monitor such patients and ascertain the diagnosis, by ruling out other causes. In a study, Bondagji managed a patient successfully with CLH of more than 11 with conservative management alone. ${ }^{23}$ In their study, though hemoglobin fell significantly from day 1 to day 4, it started improving from $5^{\text {th }}$ day. In a study by Payne et al, 3 out of 5 episodes of $\mathrm{CLH}$ with bleeding diathesis were managed successfully on conservative management. ${ }^{24}$ Another patient with massive hemoperitoneum was managed conservatively by Sikka et al. ${ }^{17}$ If there is a significant fall in hematocrit or hemoglobin, a significant increase in amount of hemoperitoneum in initial hours or there is no relief in pain over 48 hours or the initial diagnosis itself is doubtful, exploratory laparoscopy should be sought without delay. In such patients, exploratory laparoscopy is preferred over exploratory laparotomy. In a study by Kim et al, exploratory laparoscopy was done in patients with hemoperitoneum of 2.51 and conservative management was done in patients with a moderate or small amount of hemoperitoneum defined on CT scan. ${ }^{18}$ Only one prospective study is available which included 60 hemodynamically stable women out of which 30 underwent laparoscopy and 30 underwent exploratory laparotomy. ${ }^{25}$ In the previous study, women who underwent laparoscopy had a shorter hospital stay as compared to the laparotomy group $(55.33 \pm 7.67$ vs $97.77 \pm 14.4$ hours). The advantages of minimally invasive surgery are less postoperative pain and better cosmesis.

\section{ROLE OF AUTOLOGOUS BLOOD TRANSFUSION}

The main surgical management in exploratory laparoscopy is the retrieval of pooled blood followed by autologous blood transfusion. It prevents transmission of HIV, HBV and HCV. Such management is possible only at a wellequipped and advanced centre. Blood in the abdomen is irrigated with 1:10,000 dilution of heparinized Ringer's Lactate solution with frequent change of the patient's position to reverse trendelenberg. It is suctioned to Continuous autologous transfusion system, where it is concentrated and processed for re-transfusion. ${ }^{26}$ In 18 patients with ectopic or ovarian bleeding, laparoscopic retrieval of blood followed by autologous transfusion was done in a study by Yamada et al. ${ }^{27}$ In their study, mean blood loss in ovarian bleeding was $716 \pm 219 \mathrm{ml}$ and the mean blood volume reinfused processed blood was $496 \pm 138 \mathrm{ml}$.

\section{RECURRENCE}

There are higher chances of recurrence of CLH in patients on long term anticoagulation, congenital bleeding or clotting disorders. Four out of 6 patients on long term anticoagulation because of prosthetic heart valve had recurrent episodes of CLH. ${ }^{4}$ Out of 35 cases reviewed by Semchyshyn et al, 4 had recurrent episodes of CLH. Five episodes of CLH have been reported in a single patient with factor $\mathrm{V}$ deficiency, twice managed by surgery. To suppress ovulation, combined hormonal contraception can be used, however, most patients who are at risk of recurrent CLH will be on long term anticoagulation. In these patients, combined hormonal contraception is absolutely contraindicated. ${ }^{28} 75$ microgram Desogestrel has been used safely by various authors to suppress ovulation. ${ }^{2,5,29}$ Depot medroxyprogesterone acetate can be used in women on anticoagulation to suppress ovulation, however, loss of bone mineral density and fluid retention are some of the undesirable side effects. ${ }^{29,30} \mathrm{GnRH}$ analogues can also be used for the same purpose but the concern of bone mineral density loss prevents its long term use. Ulrich et al used intranasal buserelin $400 \mu \mathrm{g}$ daily along with add back therapy in the form of transdermal estradiol along with medroxyprogesterone acetate. ${ }^{31}$ In this 
way, ovarian sex steroids were replaced while cessation of ovarian function was achieved by hypogonadotropic action. Whether Warfarin adversely affects bone health remains to be clearly demonstrated in clinical trials. So, DMPA and GnRH analogues can't be used for long periods in patients receiving warfarin.

\section{CONCLUSION}

CLH can occur in reproductive age group women, more commonly in patients with coagulation or bleeding disorders or those on long term anticoagulation. It can be diagnosed easily on ultrasound. Management options include conservative management, exploratory laparoscopy, or laparotomy. The decision for the mode of treatment depends on the general condition of the patient and the amount of hemoperitoneum. Over two to three decades, the approach has shifted from laparotomy to either laparoscopy or conservative management. However, appropriate patient selection is of utmost importance in deciding further management. To avoid recurrence in high-risk patients, ovulation suppression needs to be continued.

\section{Funding: No funding sources \\ Conflict of interest: None declared \\ Ethical approval: Not required}

\section{REFERENCES}

1. Bottomley C, Bourne T. Diagnosis and management of ovarian cyst accidents. Best Pract Res Clin Obstet Gynaecol. 2009;23(5):711-24.

2. Gupta A, Gupta S, Manaktala U, Gupta MM, Solanki V. Conservative management of corpus luteum haemorrhage in patients on anticoagulation: a report of three cases and review of literature. Arch Gynecol Obstet. 2015;291(2):427-31.

3. Semchyshyn S, Zuspan FP. Ovarian hemorrhage due to anticoagulants. Am J Obstet Gynecol. 1978;131:837-44.

4. Tresch DD, Halverson G, Blick M, Keelan MH Jr. Ovarian (corpus luteum) hemorrhage during anticoagulation therapy. Ann Intern Med. 1978;88:642-6.

5. Yamakami LY, Araujo DB, Silva CA, Baracat EC, Carvalho JF. Severe hemorrhagic corpus luteum complicating anticoagulation in antiphospholipid syndrome. Lupus. 2011;20:523-6.

6. Kim JH, Jeong SY, Cho DH. Massive hemoperitoneum due to a ruptured corpus luteum cyst in a patient with congenital hypofibrinogenemia. Obstet Gynecol Sci. 2015;58:427-30.

7. Beyth RJ, Quinn LM, Landefeld CS. Prospective evaluation of an index for predicting the risk of major bleeding in outpatients treated with warfarin. Am J Med. 1998;105:91-9.

8. Cretel E, Cacoub P, Huong DL, Gompel A, Amoura Z, Piette JC. Massive ovarian haemorrhage complicating oral anticoagulation in the antiphospholipid syndrome: a report of three cases. Lupus. 1999;8:482-5.

9. Palareti G, Leali N, Coccheri S, Poggi M, Manotti C, Angelo A, et al. Bleeding complications of oral anticoagulant treatment: an inception-cohort, prospective collaborative study (ISCOAT). Italian Study on Complications of Oral Anticoagulant Therapy. Lancet. 1996;348:423-8.

10. Jamal A, Mesdaghinia S. Ruptured corpus luteum cysts and anticoagulant therapy. Int $\mathbf{J}$ Gynaecol Obstet. 2002;76:319-20.

11. 11. Jain KA. Sonographic spectrum of hemorrhagic ovarian cysts. J Ultrasound Med. 2002;21:879-86.

12. Liu X, Song L, Wang J, Liu Q, Liu Y, Zhang X. Diagnostic utility of CT in differentiating between ruptured ovarian corpus luteal cyst and ruptured ectopic pregnancy with hemorrhage. J Ovarian Res. 2018;11:5.

13. Fiaschetti V, Ricci A, Scarano AL, Liberto V, Citraro $\mathrm{D}$, Arduini S, et al. Hemoperitoneum from corpus luteal cyst rupture: a practical approach in emergency room. Case Rep Emerg Med. 2014;2014:252657.

14. Hallatt JG, Steele CH, Snyder M. Ruptured corpus luteum with hemoperitoneum: a study of 173 surgical cases. Am J Obstet Gynecol. 1984;149:5-9.

15. Raziel A, Ron-El R, Pansky M, Arieli S, Bukovsky I, Caspi E. Current management of ruptured corpus luteum. Eur J Obstet Gynecol Reprod Biol. 1993;50:77-81.

16. Murao H, Kinjyo, K. Demura T. Conservative therapy for corpus luteum hemorrhage, a review of 116 cases. Clin Gynecol Obstet. 1994;48:568-72.

17. Sikka P, Joshi B, Aggarwal N, Suri V. Corpus Luteal Hemorrhage in Coagulopathy; A Case Report with Review of Treatment Modalities. Austin J Obstet Gynecol. 2015;2:1038.

18. Kim JH, Lee SM, Lee JH, Jo YR, Moon MH, Shin J, et al. Successful conservative management of ruptured ovarian cysts with hemoperitoneum in healthy women. PLoS One. 2014;9:91171.

19. Spinelli C, Giacomo M, Mucci N, Massart F. Hemorrhagic corpus luteum cysts: an unusual problem for pediatric surgeons. J Pediatr Adolesc Gynecol. 2009;22:163-7.

20. Fong YI, Chua HW, Singh C. Diagnostic Dilemma: Acute Abdomen from Ruptured Corpus Luteum Requiring Surgical Intervention in Young Women. Thai J Obstetrics Gynecol. 2013;21:80-6.

21. Lee MS, Moon MH, Woo H, Sung CK, Jeon HW, Lee TS. Ruptured Corpus Luteal Cyst: Prediction of Clinical Outcomes with CT. Korean J Radiol. 2017;18:607-14.

22. Lee JK, Bodur S, Guido R. The management of gynecological hemoperitoneum found to be associated with a ruptured corpus luteum cyst. Gynecological Surgery 2016;13:305-11.

23. Bondagji NS. Conservative management of massive intraperitoneal hemorrhage from corpus luteum cyst in a patient on anticoagulant therapy post Fontan 
procedure. J King Abdulaziz University- medical sciences 2011;18:93-9.

24. Payne JH, Maclean RM, Hampton KK, Baxter AJ, Makris M. Haemoperitoneum associated with ovulation in women with bleeding disorders: the case for conservative management and the role of the contraceptive pill. Haemophilia. 2007;13:93-7.

25. Teng SW, Tseng JY, Chang CK, Li CT, Chen YJ, Wang PH. Comparison of laparoscopy and laparotomy in managing hemodynamically stable patients with ruptured corpus luteum with hemoperitoneum. J Am Assoc Gynecol Laparosc. 2003;10:474-7.

26. Takeda A, Sakai K, Mitsui T, Nakamura $H$. Management of ruptured corpus luteum cyst of pregnancy occurring in a 15-year-old girl by laparoscopic surgery with intraoperative autologous blood transfusion. J Pediatr Adolesc Gynecol. 2007;20:97-100.

27. Yamada T, Okamoto Y, Kasamatsu H, Mori H. Intraoperative autologous blood transfusion for hemoperitoneum resulting from ectopic pregnancy or ovarian bleeding during laparoscopic surgery. JSLS. 2003;7:97-100.

28. WHO. Medical eligibility criteria for contraceptive use, 2021. Available at: https://www.who.int/ publications/i/item/9789241549158. Accessed on 29 May 2021.

29. Connor BS, Coviello E, Fries M, John AS. Ovulation suppression to prevent hemoperitoneum and surgical menopause in anticoagulated women. JACC Case Reports 2019;1:50-4.

30. Sonmezer M, Atabekoglu C, Cengiz B, Dokmeci F, Cengiz SD. Depot Medroxyprogesterone Acetate in anticoagulated patients with previous haemorrhagic corpus luteum. European J Contracept Reproduct Health Care. 2005;10:9-14.

31. Ulrich U, Rossmanith WG. Management of peritoneal haemorrhage due to follicle rupture under anticoagulant therapy. J Endocrinol Investigat. 1994;17:351-3.

Cite this article as: Gupta A, Nayak D, Tiwari P. Changing trends in the management of corpus luteum haemorrhage. Int J Reprod Contracept Obstet Gynecol 2021;10:3261-5. 